\title{
Urban Agriculture, Waste Management and Food Security, Nepal
}

\author{
BibekDhital $^{1}$, Anusha Sharma, Santosh Adhikari
}

${ }^{1}$ Hasera Agriculture Research and training Centre, Nepal

\begin{abstract}
Urban population is growing rapidly in Nepal and similarly fallowing of land is increasing in villages. This decreases the total production and increases import of food products. In order to be self-sufficient on vegetable needs of the country, urban agriculture plays an important role. Along with food security, urban agriculture will aid in waste management, human resource utilization, health hygiene and economic growth of urban community. To find out the present situation of urban agriculture in Nepal, a case study was done in Pokhara and Dhulikhel municipality.This study will help in understanding benefits and reasons to enroll in urban agriculture. From this study, area of $150 \mathrm{~m} 2$ was found sufficient to fulfill the vegetable demand of the urban family with 4/5 siblings which will save Rs6000-8000 lyear/100sqm.
\end{abstract}

Keywords-Economic saving, Food security, Health, Nutrition security, Urban Agriculture, Waste management

\section{INTRODUCTION}

Food security exists when all people, at all times, have physical and economic access to sufficient, safe and nutritious food that meets their dietary needs and food preferences for an active and healthy life $(F A O, 2010)$.Scarcity of food in termsof both quantity and qualityresult malnutrition.

Proportion of the population living in the urban areas is increasing at present situation. $17 \%$ of the population lives in urban areas in Nepal and annual growth rate of urban population is $3.62 \%$ (Nepal demographics profile, 2014).

Urban families depend on market for vegetables and other food items. Products reaching market is not as fresh as in the farm. The urban-rural difference in vitamin A intake is marked, with rural children much more likely to receive vitamin A supplements than children in urban areas (89\% versus $81 \%),(F A O, 2010)$.

Urban agriculture can be an alternative to overcome malnutrition, food deficiency and environmental concerns to some extent. (Smit et al, 2001)

Ibrahim defined urban agriculture as the growing, processing, and distribution of food and other products through plant cultivation in cities for feeding local populations. In urban agriculture, people use spaces in productive and efficient way. Roof farming, vertical gardening, pot culture and utilizing small piece of lands are some examples of urban agriculture systems.

If the potential areas of urban and peri-urban areas are properly utilized in vegetable production, they can contribute about $70 \%$ of total vegetable need but only $23 \%$ is being produced now (http://www.cityfarmer.org/Bookdoc.pdf). And it was $46 \%$ in 2001(Smit et al, 2001). In Nepal, vegetable worth 35.27 billion was imported in 2012 and it was 50.94 billion in 2013 (Sangam Sherpa, Kathmandu post, 2014, may, 20). Maximum amount of such imported vegetables are consumed in urban areas.

Nature deficiency syndrome is being used to express such situation where children donot have enough nature around them (Richard, 2005).A kid born in urban environment doesnot get to spend time with nature. His food, his activity, his surrounding isnot natural. Reliability on junk foods, lack of exercise leads to health problem on children. A small garden which provides fresh food, little bit of greenery, where a child can experience nature is always healthy for child's physical and mental growth. Therefore this research study aimed at looking into the role of urban agriculture on food security and malnutrition.

Waste management is another challenge in urban areas. Though over $70 \%$ of the volume of the city waste is decomposable and recyclable in ground, it is not always in vogue amongst the people. Roads and other public places are full of garbage and the government is spending a lot of money to import chemical fertilizers. Practice of urban agriculture can solve this problem by large.

Realizing these situations, a study was carried out in the urban areas of Dhulikhel and Pokhara to assess the status of urban agriculture; its contribution in food security, environmental management and family recreation etc. as experienced by its practitioners; and the efficient tools and techniques to practice it. This paper presents the outcomes of the study.

\section{MATERIALS AND METHOD}

\subsection{Site of study:}

Two urban cities viz Dhulikhel (Ward no 1, 2, 3,7) in Kavre district, central development region and Pokhara 
(Ward no 5, 8, 17)in Kaski district, western development were selected. Dhulikhel lies 30KM east of Kathmandu and Pokhara lies 200KM west of Kathmandu. Ecologically Pokhara (Annual average $20.6^{\circ} \mathrm{C}$ ) is warmer as compared to Dhulikhel Annual average $16.7^{\circ} \mathrm{C}$ ). These sites were selected as site for the study as these are two of the major growing cities of the country. Study was limited in only two cities due to time and budget constraints.

\subsection{Data collection:}

This study was done as a case study. The method of data collection was questionnaire survey. Open ended structured questionnaire was prepared and pretesting was done with 5 farmers from Dhulikhel. Informants were selected randomly (but people not practicing urban agriculture werenot considered) in the community. Thirty informantsfrom both themunicipalities were interviewed. Questions mainly focused on area available for cultivation, major vegetables grown, reason for involving in urban farming and benefits from urban farming.

2.3 Data Analysis:

Ms-Excel and Ms-Word werethe tools used for data analysis. Mathematical data was tabulated and analysed in MS-Excel and report writing, data presentation was done in MS word.

\section{RESULTS AND DISCUSSIONS}

\subsection{Figure 1: Urban agriculture, waste management and food security}

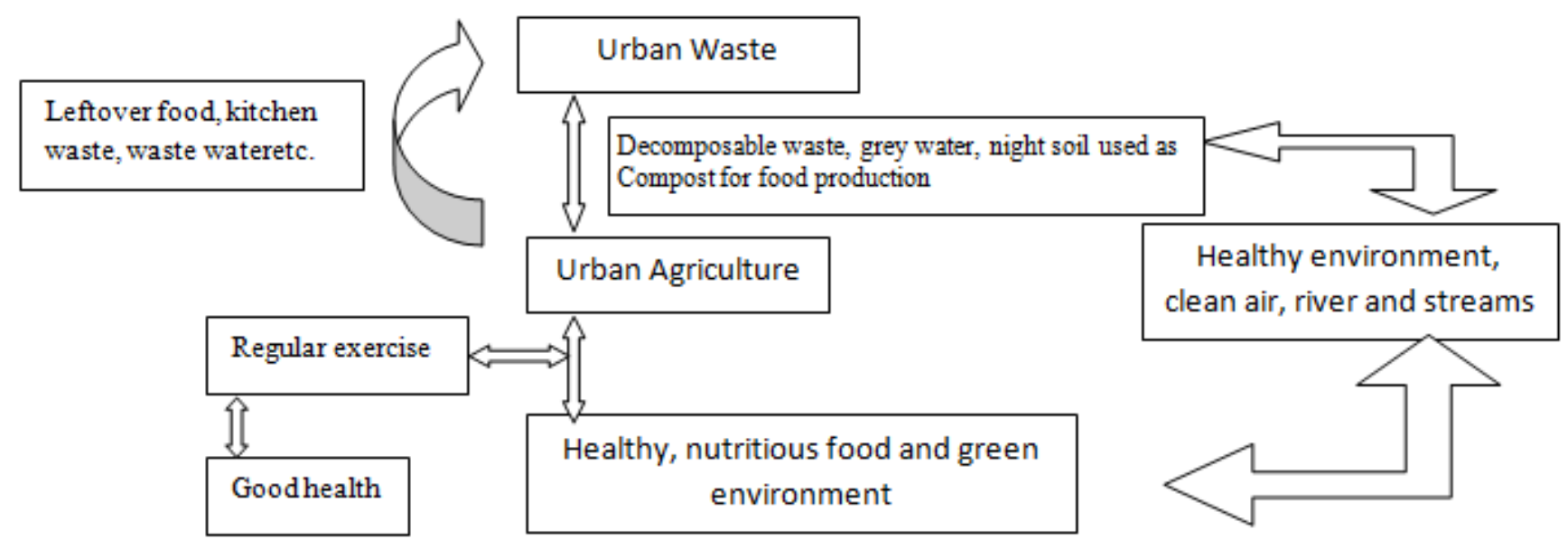

Fig.1: Urban agriculture, waste management and food security

The chart above explains the sustainability of urban agriculture. Main features of urban agriculture are waste management, healthy food and green environment.

\subsection{Proportion of households practicing urban} agriculture

About $79 \%$ of the households in Pokhara and $67 \%$ in Dhulikhel are practicing some sorts of urban agriculture. As Dhulikhel is an old town and households are connected to one another, many of the houses lack spaces for growing. Whereas in Pokhara, people have a bit more space around the house and the wall spaces are also available for cultivation.

\subsection{Reason for involvement in urban gardening:}

For those who are practicing urban agriculture, following are the key reasons to get involved

Table.1: Reasons for involvement in urban agriculture

\begin{tabular}{clll}
\hline SN & \multicolumn{1}{c}{ Reasons for involvement } & \multicolumn{2}{c}{ \% respondents } \\
\cline { 3 - 4 } & & Dhulikhel & Pokhara \\
\hline 1. & To have fresh and healthy vegetables & $100 \%$ & $100 \%$ \\
\hline 2. & To utilize of free time of the family members & $100 \%$ & $100 \%$ \\
\hline 3. & To save expenditure in vegetables and chutneys & $40 \%$ & $33.5 \%$ \\
\hline 4. & To utilize household waste & $17 \%$ & $26 \%$ \\
\hline 5. & To ensure physical exercise for the body and peace in mind & $22 \%$ & $18 \%$ \\
\hline 6. & To have fun of growing stuffs & $13 \%$ & $16 \%$ \\
\hline 7. & To increase the beauty of the house & $8 \%$ & $7 \%$
\end{tabular}

3.4Spaces and materials

(Source: Survey research) 
Kausi (roof top), Side walls, piece of lands around the house, safety tank cover, outer extension of the concrete floors, live tree trunks are the major spaces used by the practitioners in both the municipalities. Proportion of houses using wall spaces is higher in Pokhara than in Dhulikhel, because houses are mostly connected to one another even in the residential areas of Dhulikhel (Most in case of Newar community). After the earthquake in $25^{\text {th }}$
April, people have completely or partially abandoned roof farming.

Regarding the materials, people in Pokhara mostly use mud pot and real ground spaces for cultivation but in Dhulikhel people use many kinds of waste materials like cement bags, paint buckets, tin bins, fish boxes etc. It seems like people in Pokhara focus more in tidiness and people in Dhulikhel focus on cheapness.

\subsection{Major vegetables grown:}

Table.2: Major vegetables grown, by farmers while practicing urban agriculture in Dhulikhel and Pokhara, 2015/16

\begin{tabular}{lll}
\hline \multicolumn{3}{l}{ Proportion of households growing } \\
\hline Vegetables & Pokhara & Dhulikhel \\
\hline Cauliflower & $15.73 \%$ & $13.33 \%$ \\
\hline Beans & $15 \%$ & $18.33 \%$ \\
\hline Leafy vegetable & $13.4 \%$ & $21.66 \%$ \\
\hline Radish & $10.11 \%$ & $10 \%$ \\
\hline Cucurbits & $7.86 \%$ & $6.67 \%$ \\
\hline Onion / Garlic & Few & $18.33 \%$ \\
\hline Cabbage & $15 \%$ & Very few \\
\hline Other & $22.9 \%$ & $11.66 \%$
\end{tabular}

(Source: Survey research)

\subsection{Area under urban agriculture}

The survey revealed that the range of the area used for urban agriculture in both the municipalities vary from $0-300 \mathrm{~m}^{2}$. The chart below shows the frequency of different sizes of the urban agriculture garden.

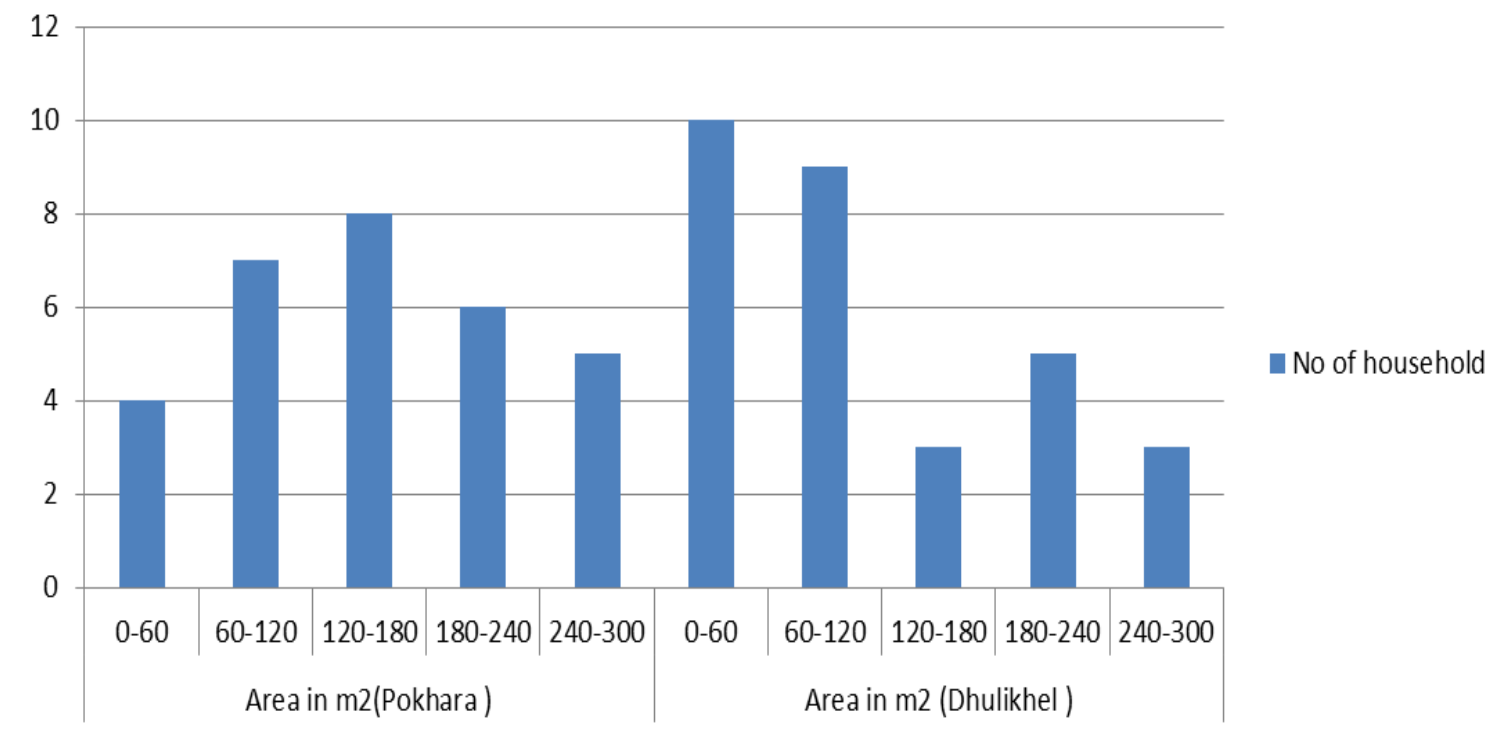

Chart.1: Land area used $\left(\mathrm{m}^{2}\right)$ and frequency ofhouseholdspracticingurban agriculture

(Source: Survey research) The chart shows that maximum number of practitioners from Pokhara has land of around 120-140 $\mathrm{m}^{2}$ and inDhulikhel, it is $0-60 \mathrm{~m}^{2}$.

\subsection{Area and food security}


Our observation shows that for a family of 4-5 members, on average $140 \mathrm{~m}^{2}$ of land in case of Pokhara and around $150 \mathrm{~m}^{2}$ of land in case of Dhulikhel is required just to fulfill the vegetable needs of the family leaving aside the fruits, dairy, aesthetic needs. The required area is smaller in Pokhara as it has hot climate and can harvest more per unit area. In some cases with better management practices, some surplus was also found when done in around $140 \mathrm{~m}^{2}$.

\section{Food security in month}

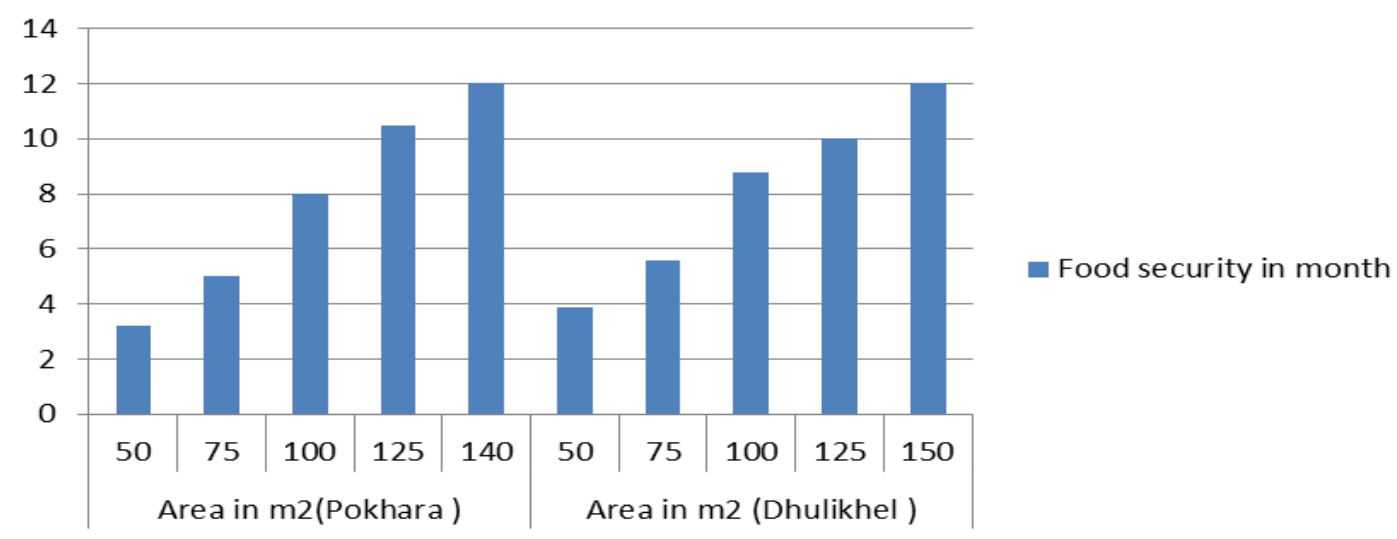

Chart.2: Relation between land area $\left(M^{2}\right)$ used for urban agriculture and vegetable sufficiency (months).

(Source: Survey research)

This chart shows that, for a family of $4 / 5$ siblings, land area of $140-150 \mathrm{~m}^{2}$ is enough (if climatic and natural factors are in favor) to fulfill the vegetable demand of the family.

\subsection{Problem faced while practicing urban agriculture:}

Following are the major problems of urban agriculture as reported by the informants-

- Costs extra money for the pots

- Fear of heavy load for the house

- Needs to irrigate more frequently

- Fear of snakes and insects at home

- Difficult to maintain tidiness at home

- Lack of space to take soil to fill the planting containers
- Neighbor often complain about shade and space encroached by plants

- Difficult to get organic manure; the ones available in the market are expensive.

\subsection{Economic saving}

All participants had the view that home grown vegetable is always cheaper than market product. It's healthy also. But the level of profit varies from farm to farm, place to place. The datashows the economic benefit gained by practicing urban agriculture in 100sqm of land during one year. It's derived by calculating the savings made by the families by not buying the vegetable from the market and deducting the cost incurred.

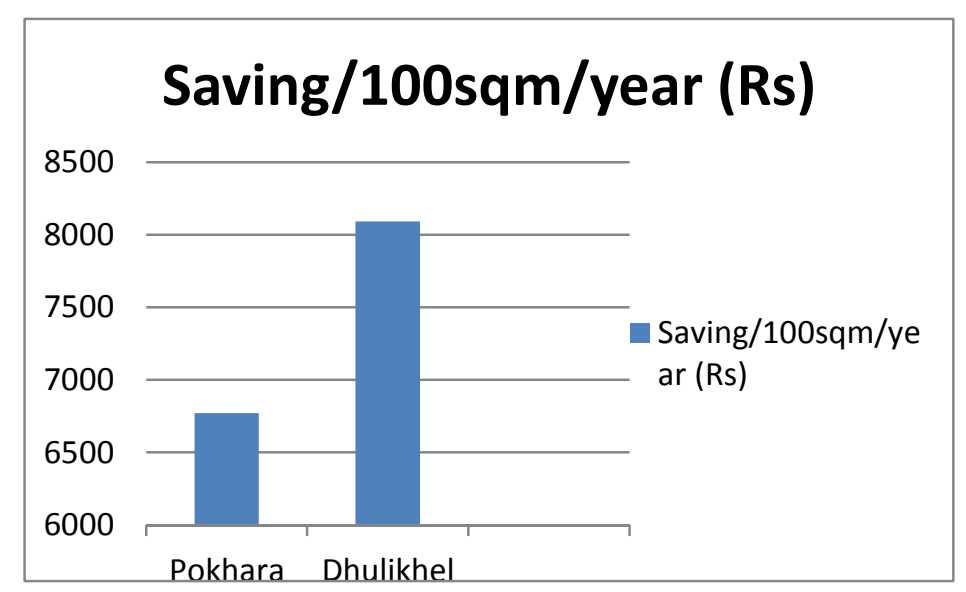

Chart.3: Economic saving in a year per $100 \mathrm{~m} 2$. 


\section{CONCLUSION}

From this study we found out that the major reason for the people to practice urban agriculture is the health security. Economic saving and recreation are the second and third priority respectively.

Our study shows that for a family with 4-5 members, average land required to provide fresh vegetable all around the year is about $140-150 \mathrm{M} 2$.Practicing urban agriculture can provide fresh vegetable of one's choice.

Most of the families producing vegetablesin their home spaces are doing organic and are also diverse. So it ensures better nutrition and better health for the family.

Use of unused house roof, walls, pots and thrown away buckets also increased the area under cultivation. Thus production of the city increased providing food security to household involved.

Finally, it is revealed that the practice of urban agriculture is widespread in Pokhara and Dhulikhel. Communities are enjoying economic, health, and environmental benefits from it.

\section{ACKNOWLEDGEMENT}

We would like to thank Mr. Govinda Sharma and Dr. BasuDevRegmi for helping throughout the research and all the farmers who volunteered in providing us information.

\section{REFERENCES}

[1] FAO, 2010. Assessment of food security and nutrition situation in Nepal. Available on (ftp://ftp.fao.org/TC/CPF/Country\%20NMTPF/Nepal/t hematic\%20studies/Food\%20Security\%20_Final_.pdf )

[2] http://www.cityfarmer.org/Bookdoc.pdf

[3] Jacsmit, Joe Nasr, AnnuRatta. 2001. Urban Agriculture: Food Jobs and Sustainable Cities, UNDP (Available on: http://www.jacsmit.com/book/Chap07.pdf ).

[4] National Demographic profile, 2014 (Available on: http://www.indexmundi.com/nepal/demographics_prof ile.html)

[5] Richard louv, 2005. Last child in the wood. Available on

(http://www.outdoorfoundation.org/pdf/LastChild.pdf)

[6] Ibrahim Game Richaela Primus 2015. Urban Agriculture. State University of New York College of Forestry and Environmental Science. (Available at: https://sustainabledevelopment.un.org/content/docume nts/5764Urban\%20Agriculture.pdf ) 